\title{
Systolic and Diastolic BP Control in Metabolic Syndrome Patients with Metadichol $\AA$ a Novel Nano Emulsion Lipid
}

\author{
PR Raghavan* \\ Nanorx Inc., USA \\ Submission: April 10, 2017; Published: May10, 2017 \\ *Corresponding author: PR Raghavan, Nanorx Inc., PO Box 131, Chappaqua, NY 10514, USA, Email: raghavan@nanorxinc.com
}

\begin{abstract}
Metadichol ${ }^{\circledR},[1]$ a nano formulation a mixture of long chain alcohols that is present in many foods like rice and sugar cane and is derived from the waste of the sugar cane industry. It is a renewable resource. Most of the clinical data in literature is a: non-nano formulation either a tablet or capsule which have not shown any efficacy.

Given its safety profile, we carried out a small open-label pilot study on diabetic patients with hypertension who had in additional comorbidities such as dyslipidemia, obesity, and hypertension. None of them were on any hypertensive medication.

Our studies on patients for 60 weeks in an open-label study @20mg per day showed that it is possible to bring about improvements in Systolic and diastolic pressure in addition to CRP, VLDL, HDL, Triglycerides and waist circumference reduction and reduction in insulin resistance. Interestingly Vitamin C levels doubled. The study showed a vast improvement over existing therapies and with no side effects minor or major to report.
\end{abstract}

Keywords: Metadichol; VDR; Inverse agonist; Protean agonist; CVD; Systolic diastolic; CRP; HDL; LDL; Albumin; Globulin; Vitamin C; Gulo; Policosanol; TNF alpha; PAI-1; MCP-1

\section{Introduction}

It is paradoxical that despite the enormous advances in antihypertensive drug therapy, the Number of people with uncontrolled hypertension has continued to rise. A new 2017 study [2] by the American Heart Association, projects that by 2035, cardiovascular disease (CVD), will become the most expensive and prevalent killer if left unchecked, will place a crushing economic and health burden on the nation's financial and health care systems. According to the study, in the next two decades, the number of Americans with CVD will rise to 131.2 million-45 percent of the total U.S. population with costs expected to reach $\$ 1.1$ trillion. There are many hypertensive drugs, but prolonged use and multi-drug use does lead over time to side effects. There is a need for a safe, cheap alternative to existing drugs. Metadichol is a Nanoemulsion of long-chain lipid alcohols (C-26, C-28, and C-30), which are commonly known as Policosanols. and it binds to VDR and which has been shown to have a role in hypertension [1,3-5].

\section{Open label study}

Fourteen patients were enrolled in Nonrandomized, Open, Single-group, study to evaluate the safety and efficacy of Metadichol in subjects with metabolic syndrome at a hospital in Bangalore, India. The dosage was $20 \mathrm{mg}$ per day. Most of the patients were on antidiabetic medication Metformin and Glucophage in addition. None of the patients were on hypertensive medication.

\section{Diagnosis and main criteria for inclusion}

The study population consisted of male or non-pregnant female patients aged 18 years of age with a previously diagnosed various medical conditions. All patients provided written informed consent to participate in the study before being screened.

The patient information sheet detailed the procedures involved in the survey (aims, methodology, potential risks, 
anticipated benefits) and the investigator explained these to each patient. The patient signed the consent form to indicate that the information had been disclosed and understood. The patient was then allowed time to consider the information presented before signing and dating the informed consent form to indicate that they fully understood the information, and willingly volunteered to participate in the study. The patient was given a copy of the informed consent form for their information. The original copy of the informed consent was kept in a confidential file in the Investigators center records.

Criteria for exclusion from the study included pregnant or lactating females any serious and uncontrolled medical conditions interfering with the study or placing the patient at unacceptable risk. Only patients who fulfilled all the inclusion criteria and did not meet any of the exclusion criteria were enrolled into the study.

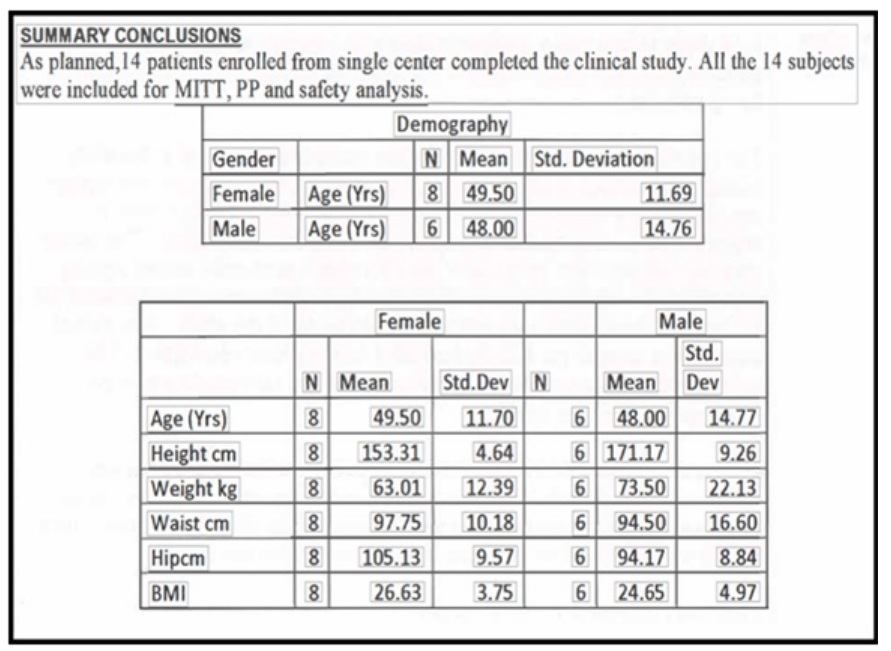

\section{Safety Results}

Metadichol was well tolerated which was confirmed by no incidences of adverse events and good compliance. Vital signs were all within the normal range during the study. There were no clinically significant abnormal findings at any of the visits in the treatment groups. Physical examination was found to be normal during the study for all the subjects. There were no clinically significant abnormal findings at any of the visits.

Analysis of Variance one way was carried out using JMP software from SAS showed that the following biomarkers were significant $<0.05$ even in the absence of controls. These were:
a) Systolic and diastolic pressure
b) hS-CRP (high sensitivity C-reactive protein)
c) Experimental VLDL
d) Vitamin C
e) $\mathrm{A} / \mathrm{G}$ ratio and Globulins
f) Triglyceride/HDL ratios

g) e-GFR a biomarker of kidney function.

\section{Discussion of Results}

The key biomarkers that are the subject of this communication are Systolic, diastolic CRP, VLDL as well as A/G ratios and Globulin. Table 1, Figures $1 \& 2$ and Table $2 \& 3$ show changes with descriptive statistics for Systolic and diastolic pressures. The most striking result was the normalization of blood pressure in 3 weeks.

Table 1:

\begin{tabular}{|c|c|c|c|}
\hline Biomarker & Change (\%) & p value & units \\
\hline Systolic Pressure & -20.13 & 0.0002 & $\mathrm{~mm} \mathrm{Hg}$ \\
\hline Diastolic Pressure & -14.2 & 0.01 & $\mathrm{~mm} \mathrm{Hg}$ \\
\hline VLDL & -58.7 & 0.00065 & $\mathrm{mg} / \mathrm{dl}$ \\
\hline $\begin{array}{c}\text { Triglyceride ratio } \\
\text { (mmol/mmol) }\end{array}$ & -34 & 0.04 & $\mathrm{mg} / \mathrm{dl}$ \\
\hline hs-CRP & -47.2 & 0.045 & $\mathrm{mg} / \mathrm{dl}$ \\
\hline Vitamin C & 100 & 0.00062 & $\mathrm{mg} / \mathrm{dl}$ \\
\hline A/G ratio & -285 & 0.00 & $\mathrm{number}$ \\
\hline Globulin & -22.9 & 0.0029 & $\mathrm{~g} / \mathrm{dl}$ \\
\hline eGFR & 42.5 & 0.0356 & $\mathrm{ml} / \mathrm{min} / 1.73$ \\
\hline HDL & 15.4 & 0.14 & $\mathrm{mg} / \mathrm{dl}$ \\
\hline Fasting Sugar & -10 & -- & $\mathrm{MG} / \mathrm{DL}$ \\
\hline Insulin Resistance & -12.5 & - & $\mathrm{number}$ \\
\hline
\end{tabular}

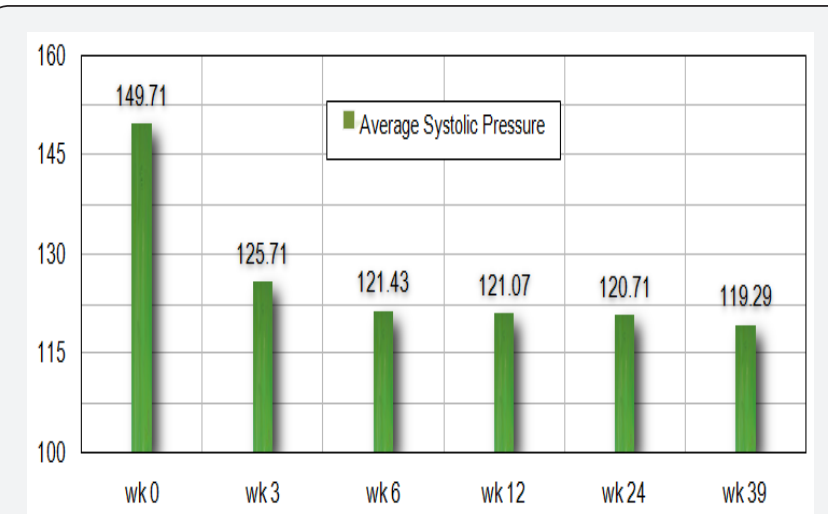

Figure 1: Average systolic pressure.

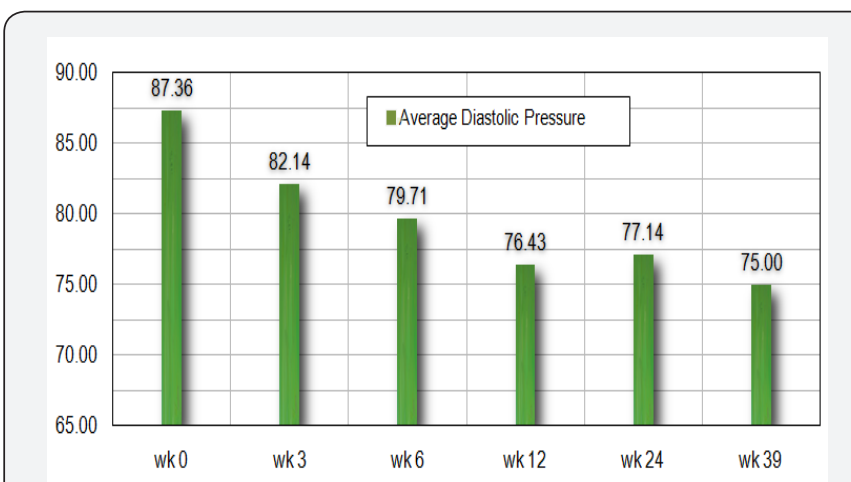

Figure 2: Average diastolic pressure. 
Table 2: Average systolic pressure.

\begin{tabular}{|c|c|c|c|c|c|c|c|}
\hline \multicolumn{8}{|c|}{ Analysis of Variance (One-Way) } \\
\hline \multicolumn{8}{|c|}{ Descriptive Statistics } \\
\hline Groups & Sample size & Sum & Mean & Variance & & & \\
\hline $\mathrm{A}$ & 14.00 & 2,096 & 149.71 & 320,120 & & & \\
\hline B & 14.00 & 1,760 & 125.71 & 223,600 & & & \\
\hline $\mathrm{C}$ & 14.00 & 1,700 & 121.43 & 208,000 & & & \\
\hline $\mathrm{D}$ & 14.00 & 1,695 & 121.07 & 207,125 & & & \\
\hline E & 14.00 & 1,690 & 120.71 & 205,500 & & & \\
\hline $\mathrm{F}$ & 14.00 & 1,670 & 119.29 & 201,900 & & & \\
\hline Total & 84.00 & & 126.32 & 311.43 & & & \\
\hline \multicolumn{8}{|c|}{ ANOVA } \\
\hline $\begin{array}{l}\text { Source of } \\
\text { Variation }\end{array}$ & d.f. & SS & MS & $\mathbf{F}$ & p-value & F crit & Omega Sqr. \\
\hline $\begin{array}{c}\text { Between } \\
\text { Groups }\end{array}$ & 5.00 & $9,520.5$ & $1,904.1$ & 9.10 & 0.00 & 2.33 & 0.33 \\
\hline Within Groups & 78.00 & $16,327.8$ & 209.3 & & & & \\
\hline Total & 83.00 & $25,848.3$ & & & & & \\
\hline
\end{tabular}

Table 3: Average diastolic pressure.

\begin{tabular}{|c|c|c|c|c|c|c|c|}
\hline \multicolumn{8}{|c|}{ Analysis of Variance (One-Way) } \\
\hline \multicolumn{8}{|c|}{ Descriptive Statistics } \\
\hline Groups & Sample size & Sum & Mean & Variance & & & \\
\hline A & 14 & 1,223 & 87.36 & 109,083 & & & \\
\hline B & 14 & 1,150 & 82.14 & 95,100 & & & \\
\hline $\mathrm{C}$ & 14 & 1,116 & 79.71 & 90,296 & & & \\
\hline $\mathrm{D}$ & 14 & 1,070 & 76.43 & 82,700 & & & \\
\hline E & 14 & 1,080 & 77.14 & 83,800 & & & \\
\hline $\mathrm{F}$ & 14 & 1,050 & 75.00 & 79,700 & & & \\
\hline Total & 84 & & 79.63 & 96.71758 & & & \\
\hline \multicolumn{8}{|c|}{ ANOVA } \\
\hline $\begin{array}{l}\text { Source of } \\
\text { Variation }\end{array}$ & d.f. & SS & MS & $\mathbf{F}$ & p-value & F crit & Omega Sqr. \\
\hline $\begin{array}{l}\text { Between } \\
\text { Groups }\end{array}$ & 5 & $1,454.63$ & 290.926 & 3.45238 & 0.00718 & 2.332 & 0.127 \\
\hline Within Groups & 78 & $6,572.93$ & 84.268 & & & & \\
\hline Total & 83 & $8,027.560$ & & & & & \\
\hline
\end{tabular}

Nesri et al. [6] found that weekly vitamin D supplementation $50,000 \mathrm{i}$ units for 12 weeks had the beneficial effect on the level of blood pressure in type 2 diabetic patients. Another recent study [7] also showed a use of 2000 IU Vitamin D showed the drop of $10 \mathrm{~mm}$ Systolic and $6 \mathrm{~mm}$ diastolic. Given that Metadichol binds to Vitamin D the results are not surprising. The effects go beyond that. Even more remarkable is its effects on lipids VLDL and also inflammation markers CRP and increase in Vitamin C levels. Lieffard et al. [8] showed that higher levels of Vitamin D are associated with lower levels of C-reactive protein.

Metadichol binds to the vitamin D receptor (VDR) as an inverse agonist. It is the only known inverse agonist of VDR known today. Calcitriol (1,25-Dihydroxy Vitamin D) is the natural ligand for the VDR and acts as an agonist. Metadichol acts an inverse agonist but more likely is a Protean agonist. Protean agonists act as both positive and negative agonists on the same receptor depending on the degree of constitutive activity that is present. If there is no constitutive activity, the agonist would be an active agonist. When constitutive activity is present, the Protean agonist would be an inverse agonist [9]. In addition to VDR binding, Metadichol shares cross-reactivity with other nuclear receptors, like PPAR gamma [10], which may explain its activity against a broad range of biomarkers.

Even more striking is that Vitamin C levels doubled. It is well known that our ancestors had a functioning gene GULO that converted glucose into Vitamin C [11]. Humans once made 
vitamin $\mathrm{C}$ in their liver by the production of four enzymes which convert circulating sugars into ascorbic acid (vitamin C). Humans today only make 3 of the four enzymes required to convert glucose (sugar) into Ascorbic acid. A progressive mutation at some time in past generations deactivated the gene for the enzyme gluconolactone oxidase and slowly as the mutation progressed the synthesis of vitamin $\mathrm{C}$ came to an end in humans. The human need for Vitamin $\mathrm{C}$ being fulfiiled by exogenous sources today. This has led to inactivity of the enzyme L-gulonolactone [12].

Mammals who make their vitamin C can live 8-10 times beyond their age of physical maturity. Mammals without this ability have a difficult time reaching 3-4 times. Researchers believe the reinstallation of the guano-lactone oxidase enzyme in humans would extend the lifespan of humans $[13,14]$.

A study over a 12-16-year period showed that males with the highest blood serum levels of vitamin $\mathrm{C}$ experienced a 57 percent drop in their risk of dying from any cause compared to males with low circulating levels of vitamin C [15]. Among men and women ages 45-79 years, just a 50 milligram increase in vitamin $\mathrm{C}$ consumption was enough to reduce the relative allcause mortality rate by 20 percent [16].

Another study published in 2001 also confirms a 25-29 percent decreased all-cause mortality rate among adults with normal to high circulating levels of vitamin C [17].

Since vitamin C is an antioxidant and reduces C-reactive protein (CRP)-a substance that can support the progression of CVD [18]. In fact, in a study of active and passive smokers, vitamin C supplementation (515mg daily) resulted in a 24-percent reduction in plasma CRP. Ascorbate stimulates the immune system and can help those with impaired immunity $[19,20]$. Low serum 25(OH)D levels are associated with significantly higher very low density lipoproteins [21].

Today's approach in drug research is a lock and key, with a drug acting as a selective 'key' that fits into the 'lock' of a specific drug target. Given the many side effects of drugs and to overcome it the search for high selective ligands has been the approach of the drug discovery community. This has not delivered any tangible benefits. Many useful drugs act via modulation of multiple proteins rather than single targets. Anti-psychotic drugs commonly exhibit a broad spectrum of activities across entire families of serotonin and dopamine receptors. Protein kinase inhibitors like Sutent and Gleevec, have demonstrated that their anticancer effects are most likely due to their action on multiple signaling kinases [22].

Ylldirım et al. [23] suggested that there are many keys for each lock is more common than one key to open many locks. Their hypothesis based on available data of drug action using network biology provided insights into how we can improve drug discovery for complex diseases. Medicines for many disease states may require multiple activities to be efficacious, together with the observation that perturbed biological networks is more important than individual targets. Such an approach has been highlighted and advocated by Andrew Hopkins [24].

Effective drugs act via modulation of multiple proteins rather than single targets. Metadichol does just that. It seems to be operate by optimizing multiple activities, and balancing druglike properties and eliminating undesirable off target effects. The inverse/protean activity exhibited by Metadichol leads to it acting on more than one target, VDR, PPAR gamma as well as inhibition of cytokines like TNF-alpha, MCP-1, PAI-1 and also the endogenous increase of Vitamin C levels which we have shown in our Rat studies [1]. Given the range and breadth of actions of Metadichol the results suggest that it mimics the effects of 1,25 , dihydroxy Vitamin D3 but without the toxic effect secondary to calcemia which limits its use as a pharmaceutical agent [25]. Metadichol is the first example of a smart molecule that can simultaneously modulate multiple targets which could pave the way to successful treatment of many of these challenging diseases [26-31].

\section{Conclusion}

The results of this study demonstrate that Metadichol has a better Safety and efficacy ratio profile as evidenced by the Improvement of the levels Various biomarkers especially Systolic and diatonic blood pressure and markers of CVD like CRP and VLDL. It has the potential to be an effective approach in overcoming hypertension and markers related to CVD diabetes and lipid disorders. Metadichol has a particle size of less than $60 \mathrm{~nm}$ and has the potential to serve as an anti-hypertensive and anti-inflammatory molecule with a broad spectrum of activity, particularly given that its constituents (long-chain lipid alcohols) are present in foods commonly daily and has shown any toxicity even at doses of up to $5000 \mathrm{mg} / \mathrm{kg}$ [31-33]. Metadichol could be used as a preventive nutritional supplement as a cheaper and a far effective substitute to prescription drugs, which have been largely ineffective in hypertension and many other chronic diseases and have many side effects that add to health care costs.

\section{References}

1. Raghavan PR (2015) US Patents: 8,722,093 (2014), 9,034,383 (2015) and 9,006,292 (2015).

2. Cardiovascular disease: a costly burden for America. Projections through 2035. American Heart Association p. 1-16.

3. Judd SE, Nanes MS, Ziegler TR, Wilson PW, Tangpricha V (2008) Optimal Status attenuates the age-associated increase in systolic blood pressure in white Americans: results from the third National Health and Nutrition Examination Survey. Am J Clin Nutr 87(1): 136-141.

4. Lind L, Hänni A, Lithell H, Hvarfner A, Sörensen OH, et al. (1995) Vitamin D is related to blood pressure and other cardiovascular risk factors in middle-aged men. Am J Hypertens 8(9): 894-901.

5. Kristal-Boneh E, Froom P, Harari G, Ribak J (1997) Association of calcitriol and blood pressure in normotensive men. Hypertension 30(5): 1289-1294.

6. Nasri H, Behradmanesh S, Ahmadi A, Rafieian-Kopaei M (2014) Impact of oral vitamin D (cholecalciferol) replacement therapy on blood 
pressure in type 2 diabetes patients; a randomized, double-blind, placebo-controlled clinical trial. J Nephropathol 3(1): 29-33.

7. Al-Dujaili EA, Munir N, Iniesta RR (2016) Effect of vitamin D supplementation on cardiovascular disease risk factors and exercise performance in healthy participants: a randomized placebo-controlled preliminary study. Ther Adv Endocrinol Metab 7(4): 153-165.

8. Liefaard MC, Ligthart S, Vitezova A, Hofman A, Uitterlinden AG, et al. (2015) Vitamin D and C-Reactive Protein: A Mendelian Randomization Study. PLoS One 10(7): e0131740.

9. Neubig RR (2007) Missing Links: Mechanisms of Protean Agonism. Mol Pharmacol 71(5): 1200-1202.

10. Raghavan PR, unpublished results.

11. Inai Y, Ohta Y, Nishikimi M (2003) The whole structure of the human nonfunctional L-gulono-gamma-lactone oxidase gene--the gene responsible for scurvy--and the evolution of repetitive sequences thereon. J Nutr Sci Vitaminol (Tokyo) 49(5): 315-319.

12. Burns JJ (1959) Biosynthesis of l-ascorbic acid; basic defect in scurvy. J Am J Med 26(5): 740-748.

13. Cowley G, Church V (1992) Live longer with vitamin C: A new study finds that a little more is a lot better. Newsweek, p.60.

14. Enstrom JE, Kanim LE, Klein MA (1992) Vitamin C intake and mortality among a sample of the United States population. Epidemiology 3(3): 194-202.

15. Loria CM, Klag MJ, Caulfield LE, Whelton PK (2000) Vitamin C status and mortality in US adults. Am J Clin Nutr 72(1): 139-145.

16. Khaw KT, Bingham S, Welch A, Luben R, Wareham N, et al. (2001) Relation between plasma ascorbic acid and mortality in men and women in EPIC-Norfolk prospective study: a prospective population study. Lancet 357(9257): 657-663.

17. Simon JA, Hudes ES, Tice JA (2001) Relation of serum ascorbic acid to mortality among US adults. J Am Coll Nutr 20(3): 255-263.

18. Block G, Jensen C, Dietrich M, Norkus EP, Hudes M, et al. (2004) Plasma $\mathrm{C}$-reactive protein concentrations in active and passive smokers: influence of antioxidant supplementation. J Am Coll Nutr 23(2): 141147.

19. Juraschek SP, Guallar E, Appel LJ, Miller ER (2012) Effects of vitamin C supplementation on blood pressure: a meta-analysis of randomized controlled trials. Am J ClinNutr 95(5): 1079-1088.
20. Nicol M (1993) Vitamins and immunity. Allergy Immunol 25(2): 70-73.

21. Lupton JR, Faridi KF, Martin SS, Sharma S, Kulkarni K, et al. (2016) Deficient serum 25-hydroxyvitamin D is associated with an atherogenic lipid profile: The Very Large Database of Lipids (VLDL-3) study. J Clin Lipidol 10(1): 72-81.

22. Roth BL, Sheffler DJ, Kroeze WK (2004) Magic shotguns versus magic bullets: selectively non-selective drugs for mood disorders and schizophrenia. Nat Rev Drug Discov 3(4): 353-359.

23. Yildirim MA, Goh KI, Cusick ME, Barabási AL, Vidal M (2007) Drugtarget network. Nat Biotechnol 25(10): 1119-1126.

24. Hopkins AL (2008) Network pharmacology: the next paradigm in drug discovery. Nat Chem Biol 4(11): 682-690.

25. Plum LA, DeLuca HF (2010) Vitamin D, disease and therapeutic opportunities. Nat Rev Drug Discov 9(12): 941-955.

26. Raghavan PR (2017) Improving Longevity with Metadichol $®$ by inhibiting Bcat-1 Gene. Journal of Aging Science. 5: 174.

27. Raghavan PR (2016) In vitro Inhibition of ZikaVirus by Metadichol®. A Novel Nano Emulsion Lipid. J Immunol Tech Infect Dis 5: 4.

28. Raghavan PR (2016) Inhibition of Dengue and other enveloped viruses by Metadichol $\AA$, a novel nano emulsion lipid. Journal of the science of Healing Outcomes. 8(31): 19-25.

29. Raghavan PR (2010) Case Report of Type 1. Diabetes. Journal of the Science of Healing Outcomes 2(8-9): 24.

30. Raghavan PR (2016) Metadichol and Type 2 Diabetes A case report. Journal of the Science of Healing Outcomes 8(32): 5-10.

31. Alemán CL, Más R, Hernández C, Rodeiro I, Cerejido E, et al. (1994) A 12-month study of policosanol oral toxicity in Sprague Dawley rats. Toxicol Lett 70(1): 77-87.

32. Alemán CL, Más Ferreiro R, Noa Puig M, Rodeiro Guerra I, Hernández Ortega C, et al. (1994) Carcinogenicity of policosanol in SpragueDawley rats: A 24-month study. Teratog Carcinog Mutagen 14(5): 239249.

33. Alemán CL, Puig MN, Elías EC, Ortega CH, Guerra IR, et al. (1995) Carcinogenicity of policosanol in mice: An 18-month study. Food Chem Toxicol 33(7): 573-578.

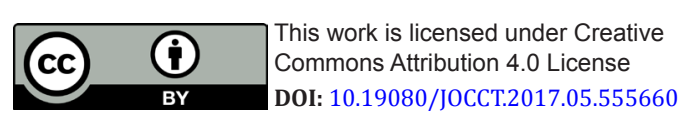

\section{Your next submission with Juniper Publishers will reach you the below assets}

- Quality Editorial service

- Swift Peer Review

- Reprints availability

- E-prints Service

- Manuscript Podcast for convenient understanding

- Global attainment for your research

- Manuscript accessibility in different formats

( Pdf, E-pub, Full Text, Audio)

- Unceasing customer service

Track the below URL for one-step submission https://juniperpublishers.com/online-submission.php 